\title{
SIMULAÇÃO DE MOVIMENTAÇÃO DE DUNAS NA ZONA COSTEIRA DO PARQUE NACIONAL DOS LENÇÓIS MARANHENSES
}

\author{
Vera Raquel Mesquita Costa ${ }^{(a)}$, Denilson da Silva Bezerra ${ }^{(b)}$ Camila Everton Guterres $^{(\mathrm{c})}$, \\ Aurivelton da Conceição Coelho ${ }^{(\mathrm{d})}$, André Luis Silva dos Santos ${ }^{(\mathrm{e})}$, Antonia da Silva Sousa ${ }^{(\mathrm{f})}$ \\ (a) Engenharia Ambiental, Universidade Ceuma, Campus Renascença, vera-raquel-camposlindos@ hotmail.com \\ (b)Ciências Exatas, Universidade Ceuma, Campus Renascença, denilson_ca@yahoo.com.br
}

Eixo: GEOTECNOLOGIAS E MODELAGEM ESPACIAL EM GEOGRAFIA FÍSICA

\section{RESUMO}

\begin{abstract}
Apresentamos um MDE de dunas na região do Parque Nacional dos Lençóis Maranhenses, para apoiar estudos de modelagem para simular como as dunas são formadas usando imagens de satélite multi-temporais e verdade do solo com a coleta de dados através do posicionamento cinemático GNSS. A área de estudo está localizada na zona de contato entre três grandes ecossistemas neotropicais: Amazônia, Caatinga e Cerrado. O PNLM é uma unidade de conservação brasileira de proteção integral da natureza, localizada no nordeste do Maranhão. A aplicação GNSS nessa área ocorreu devido à dificuldade de mapear as características das dunas através de métodos convencionais. Registramos 5.605 pontos geodésicos de características de dunas na área. Os resultados mostraram que para a pesquisa (novembro / 2015) uma duna com $11.485 \mathrm{~m}$ a altura máxima e a base do solo com $0.337 \mathrm{~m}$.
\end{abstract}

Palavras-chaves: Modelos Digitais de Elevação (MDE), Erosão Costeira, Parque Nacional dos Lençóis Maranhenses.

\section{INTRODUÇÃO}

A zona costeira, ou faixa litorânea, corresponde à zona de transição entre o domínio continental e o domínio marinho, e está sujeita a continuas alterações morfodinâmicas originadas de processos continentais, marinhos e/ou antrópicos. Esses processos, determinantes na formação de distintos tipos de costas, englobam oscilações do nível do mar e dinâmica erosiva e deposicional associada à ação das ondas, marés, correntes e dinâmicas eólicas. Sendo assim, constitui-se de um ambiente altamente instável apresentando grande variabilidade temporal e espacial (BAPTISTA NETO et al., 2004).

A região da costa brasileira detém um conjunto complexo de elementos climáticos, oceanográficos e geomorfológicos que condicionam os processos atuantes em determinados trechos do segmento litorâneo brasileiro que modelam sua morfodinâmica, o que induz vários compartimentos distintos, Estes são: Litoral Amazônico, Litoral Nordestino ou das Barreiras, Litoral Oriental e Litoral Sudeste.

No Litoral Nordestino brasileiro é marcante a presença de sistemas dunares. As dunas são caracterizadas como sendo depósitos de sedimentos que são formadas pela ação do vento sobre a areia com a presença ou não de vegetação (CORDAZZO e SEELIGER, 1988; Cadaval e Albuquerque, 2015). As dunas costeiras se destacam por atuar na proteção às transgressões do nível do mar e constituem ecossistemas de grande importância e vulnerabilidade às ações naturais e antrópicas (Carneiro, 2011) 
OS DESAFIOS DA GEOGRAFIA FÍSICA NA FRONTEIRA DO CONHECIMENTO Instituto de Geociências - Unicamp

Campinas - SP

28 de Junho à 02 de Julho de 2017

A área de estudo está localizada na zona de contato entre três grandes ecossistemas neotropicais: Amazônia, Caatinga e Cerrado, em uma área denominada de Parque Nacional dos Lençóis Maranhenses (PNLM). O PNLM está localizado no estado do Maranhão, no nordeste do Brasil (coordenadas centrais: $02^{\circ} 31^{\prime} 02$ "S, $43^{\circ} 011^{\prime} 54 " \mathrm{~W}, \mathrm{WGS} 84$ ). A área do parque (cerca de 155.000 hectares) é composta de dunas de areia, lagoas de água doce, restingas, lagos, manguezais e $70 \mathrm{~km}$ de praia. Os campos de dunas desta área surgiram das variedades de sedimentos devidas a retrogradações de depósitos sedimentares (formação de Barreiras da Idade Terciária), o correspondente alargamento da plataforma continental, sucessivas transgressões marinhas desde o Pleistoceno e insumos de sedimentos fluviais dos principais rios da região (Castro e Piorski 2002).

O PNLM possui sinuosas cadeias de dunas intercaladas por lagoas de água doce, rasa, cristalina, e temporárias que deslumbram turistas do mundo todo. Por ser um ambiente natural diferenciado quanto à gênese, fauna e flora, é o mais importante campo de dunas do litoral brasileiro e um dos mais significativos do mundo por ser o único "deserto" com água conhecido no planeta (REGO e ALBURQUERQUE, 2007).

Diferentemente de outros desertos, os Lençóis recebem relativamente muita água, chegando a até 2 mil milímetros de precipitação anual (UEMA, 2002). Mais de 90\% dessa chuva, porém, é precipitada entre janeiro e julho, quando é absorvida rapidamente pela areia elevando o nível do lençol freático acima do solo e formando as lagoas temporárias entre as cadeias de dunas, que quase não se movimentam nessa época do ano devido à umidade e à escassez de vento. Atingindo aproximadamente um metro de profundidade na estação chuvosa, as lagoas secam gradativamente ao longo do segundo semestre, quando os ventos predominam, soprando sempre do leste, alcançando a velocidade de 70 quilômetros por hora, período que as dunas mais se movimentam.

Os Lençóis Maranhenses é composta pelos maiores campos de dunas do Brasil (Miranda et al., 2012), espalhada por milhares de lagoas de água doce formadas anualmente por chuvas. Em 1981, a área foi convertida em um parque chamado Parque Nacional Lençóis Maranhenses.

Modelos Digitais de Elevação (MDE) são informações importantes nos estudos de dinâmica costeira em distintas aplicações porque fornecem um modelo da topografia da superfície do terreno em três dimensões e são fundamentais para a avaliação de riscos de inundações em áreas baixas (Santos et al., 2014).

Informações integradas podem ser utilizadas em questões relacionadas à evolução costeira, tais como na alimentação dos modelos de prognósticos na identificação das zonas de risco, no auxílio aos estudos de uso e ocupação sustentável do solo em áreas de intensa dinâmica costeira (erosão/acresção) sobre atividades antrópicas, na análise da elevação do nível do mar e de fenômenos climáticos globais como o El Niño e a La Niña (SOUTO et al., 2004; ESTEVES et al., 2006; KLEMAS, 2011). 


\section{OS DESAFIOS DA GEOGRAFIA FÍSICA NA FRONTEIRA DO CONHECIMENTO \\ Instituto de Geociências - Unicamp \\ Campinas - SP \\ 28 de Junho à 02 de Julho de 2017}

O objetivo deste trabalho é gerar um Modelo Digital de Elevação (MDE) de dunas do PNLM utilizando geodésia de alta precisão para subsidiar estudos de modelagem para simular como as dunas são formados utilizando imagens multitemporais de satélite e a verdade de campo com a coleta de dados através do posicionamento cinemático GNSS.

\section{METODOLOGIA}

\section{Área de Estudo}

A área objeto de estudo é um setor de dunas no povoado Caburé próximo a foz do Rio Preguiças, município de Barreirinhas, conforme Figura 1, localizado na região dos Lençóis Maranhenses, entre os meridianos $2^{\circ} 42^{\prime} 21^{\prime \prime}$ e $2^{\circ} 35^{\prime} 09^{\prime \prime}$ de longitude oeste e entre os paralelos $42^{\circ} 470^{\prime} 15^{\prime \prime}$ e $42^{\circ} 39^{\prime} 56^{\prime \prime}$ de latitude sul. Nesta região ocorre a transição entre a Pré-Amazônia e o Sertão Brasileiro e amplos campos de dunas intercalados com o manguezal, que são restritos a foz dos rios e baías (CITação).

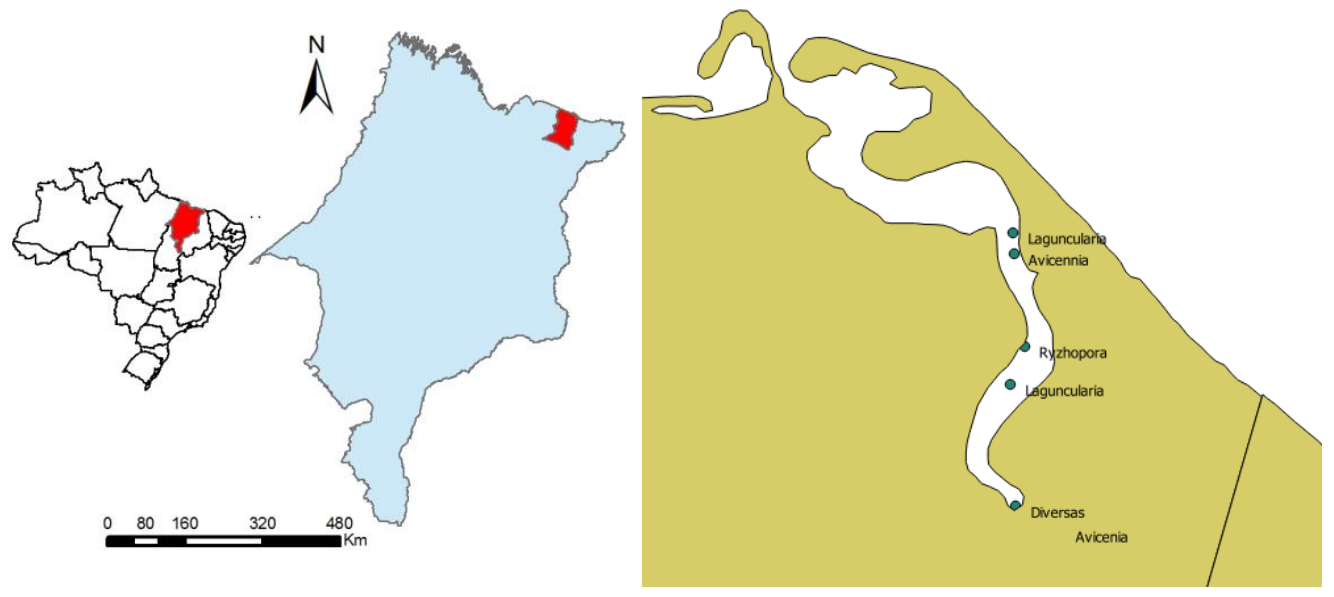

Figura 01 - Mapa de Localização da área de estudo

\section{MAPEAMENTO}

Para identificar o local para coleta das dunas utilizou-se imagens orbitais imageadas em distintas datas. Foram selecionadas duas datas de imagens do sensor LANDSAT 5-TM (1986) e LANDSAT 8-OLI (2014), disponíveis no site do Serviço Geológico dos Estados Unidos (USGS 2014) e do acervo do Grupo de Informática Aplicada e Geoprocessamento (GIAGeo). Efetuou-se o levantamento dos campos de dunas em diferentes datas, para selecionar o local mais apropriado para o levantamento geodésico que fosse de fácil acesso e que estivesse próximo de uma região mudanças evidente da linha de costa.

As imagens foram georreferenciadas e em seguida foram realizadas composições coloridas RedGreen-Blue (RGB) no software ER-Mapper ${ }^{\circledR}$ v.7.1. No software ArcGIS foi definidos a área que, 
OS DESAFIOS DA GEOGRAFIA FÍSICA NA FRONTEIRA DO CONHECIMENTO Instituto de Geociências - Unicamp

Campinas - SP

28 de Junho à 02 de Julho de 2017

temporalmente apresentou uma grande diferença da linha de costa, sendo escolhida as dunas próximas ao povoado Caburé, próximo a foz do rio Preguiças.

Foi realizado levantamento geodésico pelo posicionamento e altimetria GNSS, seguindo a metodologia proposta por Santos; Amaro; Souto (2011) e testada e validade por Santos et al., (2015) para geração do MDE. A geração do MDE consistiu nas etapas de: Aquisição de dados, processamento de dados, geração do MDE.

Para a etapa de aquisição esta foi subdividida em: (1) implantação de marco geodésico de apoio; (2) levantamento planialtimétrico das dunas.

\section{Implantação do Marco Geodésico de Apoio Básico e Levantamento GNSS}

O marco geodésico é um Marco de Apoio Básico (MAB) foi implantado para realizar os levantamentos planialtimétricos pelo método geodésico, e obterem-se vetores curtos no processamento. A implantação do MAB, chamado de RGLMA-01, seguiu a metodologia definida por Santos \& Amaro (2011), além das especificações do IBGE (1998) na norma NBR 14166 e fixadas a partir das estações da Rede Brasileira de Monitoramento Continuo (RBMC) do Sistema Geodésico Brasileiro (SGB) (IBGE 2010).

O transporte de coordenadas foi ser executado com aparelho GPS Geodésico L1/L2 da marca Topcon modelo Hiper+ e processados com o software Topcon Tools para a obtenção das coordenadas geodésicas, elevação elipsoidal e desvios padrão, conforme relatório de pós-processamento, com as estações da RBMC do IBGE utilizando São Luís e Teresina.

O método de posicionamento estático é a técnica tradicional de medição por GNSS e consiste na coleta de dados para uma sessão de longa duração (por 1 a 8 horas). Este método é ideal para distâncias maiores do que $20 \mathrm{~km}$ (bases longas) sendo utilizado para implantação, controle, densificação de redes geodésicas e vários outros trabalhos de precisão (Mônico, 2008).

O levantamento planialtimético geodésico da superfície das dunas foi realizado pelo posicionamento relativo cinemático pós-processado GNSS (Postprocessed Kinematic - PPK) com o receptor móvel adaptado em um quadriciclo motorizado, permitindo o aumento da produtividade na aquisição de dados. O receptor utilizado foi do modelo Trimble R3 que possui precisão horizontal de $10 \mathrm{~mm}+1$ ppm e vertical é de $20 \mathrm{~mm}+1$ ppm, operando com taxa de gravação de 1 segundo.

Como estação de referência ao posicionamento relativo foi utilizada o MAB RGLMA-01 (Figura 4), a partir do qual foi possível utilizar bases curtas aos posicionamentos GNSS, ou seja, a determinação de coordenadas geodésicas com alta precisão. 


\section{Processamento e Geração do MDE}

A etapa de processamento dos dados consistiu de duas etapas: determinação das coordenadas geodésicas e determinação das altitudes ortométricas. As coordenadas geodésicas (latitude, longitude e altitude geométrica) e os erros padrões dos pontos levantados em campo foram obtidos nos processamentos e ajustamentos dos dados GNSS, realizados com o programa Topcon Tools versão 7.5.1, com solução do tipo fixa, nível de confiança de $68 \%$, e com o erro padrão admissível dos vetores de $10 \mathrm{~cm}$. As altitudes ortométricas foram calculadas a partir das altitudes geométricas, referidas à superfície do elipsóide de revolução (MONICO, 2008), utilizando a ondulação geoidal (N), obtidas com o modelo geoidal MAPGEO 2015, segundo $\mathrm{H}=\mathrm{h}-\mathrm{N}$.

Na geração dos MDE foi utilizada a interpolação por triangulação com uso da técnica TIN (Triangular Irregular Network) com a triangulação de Delaunay utilizado o software ArcGIS, versão 9.3, da ESRI ${ }^{\circledR}$. Com este procedimento, as curvas de nível (isolinhas) são traçadas a partir da disposição original dos dados, não ocorre extrapolação e as estimativas limitam-se à área resultante da soma das áreas dos triângulos (MATOS, 2005; ZANARDI, 2006; SANTOS; AMARO; SOUTO, 2011). A interpolação pelo método TIN foi utilizada, pois, de acordo com avaliações realizadas em Amaro et al. (2013), é a mais adequada para a representação de superfícies de praias arenosas, quando comparada com outros interpoladores.

\section{RESULTADOS E DISCURSSÃO}

As Figuras 2a e 2b apresentam as imagens de satélite de 1986 e 2014, com desataque para a área de estudo. A nuvem de pontos obtidas no levantamento geodésico realizados nas dunas, em janeiro de 2016. Foram coletados respectivamente 1.010 pontos amostrais com distribuição irregular, distribuídos em função das diferentes feições morfológicas encontradas na época do levantamento. As precisões obtidas nos processamentos de dados GNSS tiveram média de 1,0 $\mathrm{cm}$ em N, 2,4 cm em E, e $2,5 \mathrm{~cm}$ em h para as coordenadas UTM. 


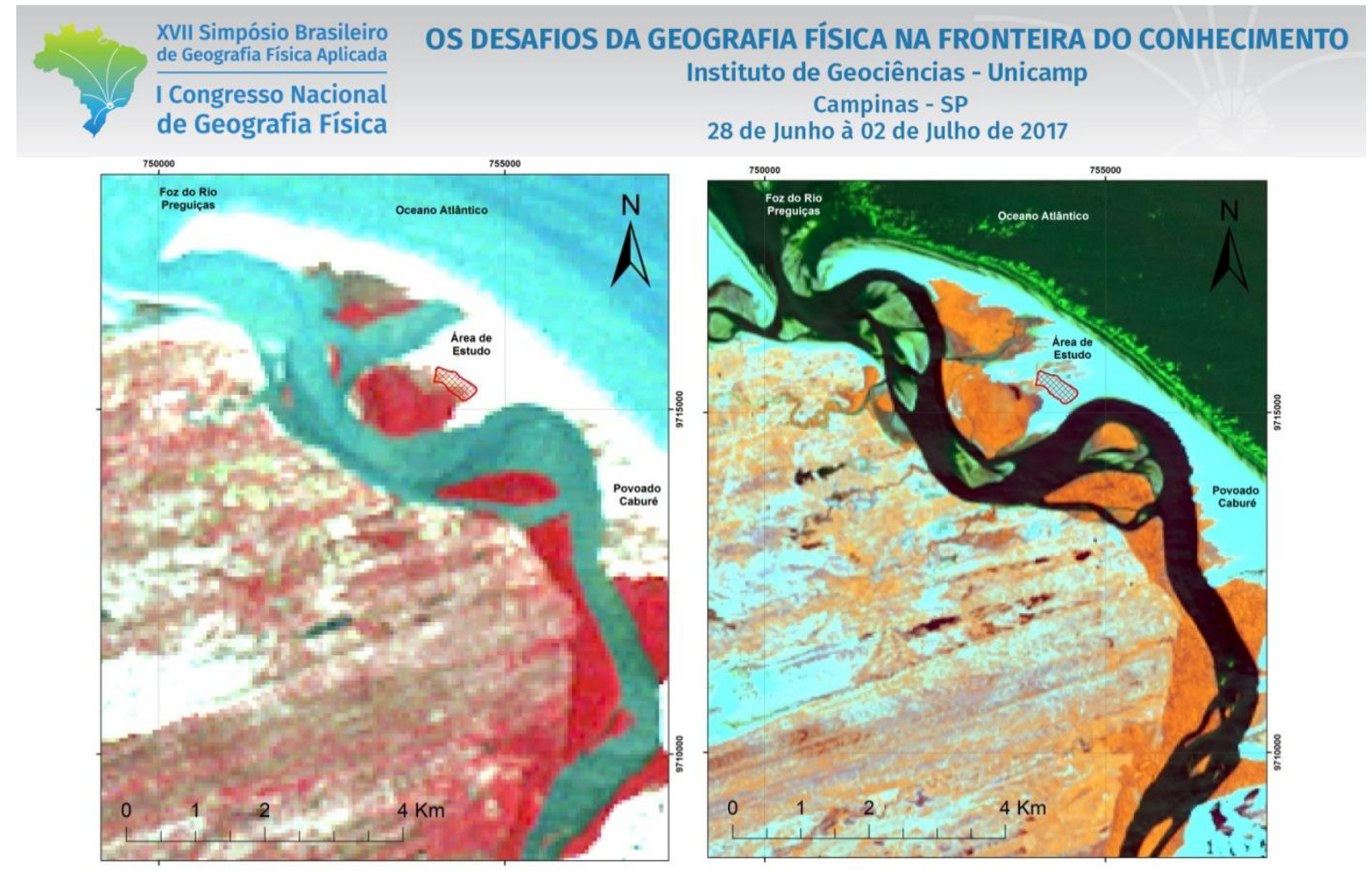

Figura 2 - Imagem (a) Landsat 5TM para o ano de 1986 com a composição colorida RGB_321com destaque em vermelho para os manguezais e branco para a praia e campo de dunas e (b) Landsat 8 OLI para o ano de 2014 com a composição colorida RGB_NDVI_PC1_B7 (NDVI, Principal componente 1 e Banda 7) com destaque em laranja para os manguezais e cyano claro para a praia e campo de dunas.

A Figura 3 e apresenta a nuvem de pontos obtidas no levantamento geodésico realizados nas dunas, em janeiro de 2016. Foram coletados respectivamente 1.010 pontos amostrais com distribuição irregular, distribuídos em função das diferentes feições morfológicas encontradas na época do levantamento. As precisões obtidas nos processamentos de dados GNSS tiveram média de $1,0 \mathrm{~cm}$ em $\mathrm{N}, 2,4 \mathrm{~cm}$ em E, e 2,5 cm em h para as coordenadas UTM. 


\section{OS DESAFIOS DA GEOGRAFIA FÍSICA NA FRONTEIRA DO CONHECIMENTO Instituto de Geociências - Unicamp Campinas - SP 28 de Junho à 02 de Julho de 2017}
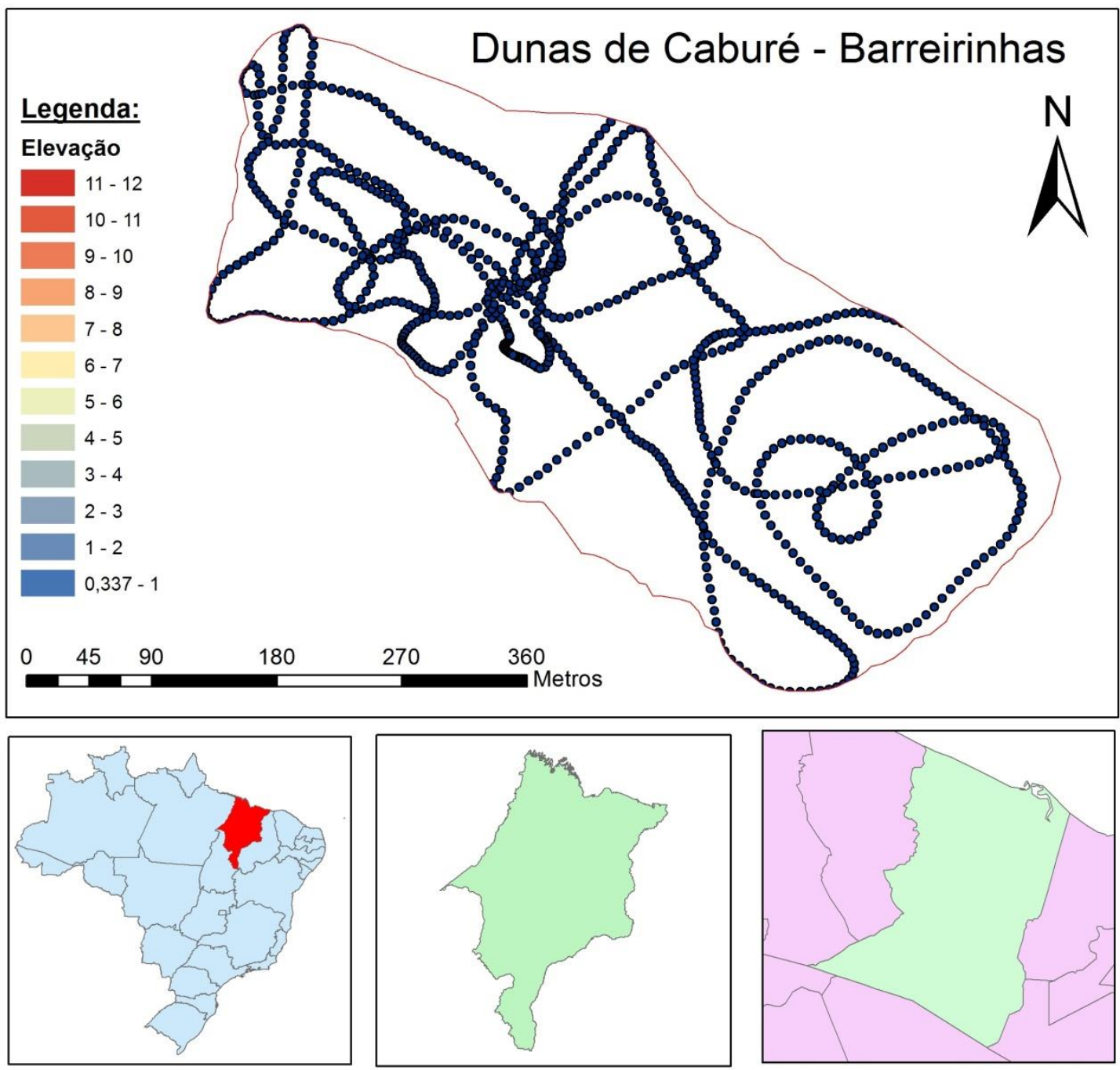

Figura 3 - Nuvens de pontos do levantamento geodésico realizado nas dunas do povoado Caburé, em janeiro de 2016.

A Figura 4 apresenta o MDE da área de estudo, obtido pelo método geodésico. O sistema de projeção utilizado foi o plano UTM (Fuso $23 \mathrm{~S}$ ) e as curvas de nível geradas tiveram eqüidistância vertical de 0,20 m - compatível com a acurácia dos modelos. Para melhorar a visualização dos modelos nas escalas adotadas foi aplicada uma tabela de cores com variações de $0,50 \mathrm{~m}$, do azul (região mais baixa) ao vermelho (região mais alta). Observa-se que as altitudes tem uma amplitude de 11,66m variando de $12,00 \mathrm{~m}$ para as regiões mais altas e $0,34 \mathrm{~m}$ nas regiões interdunares. 

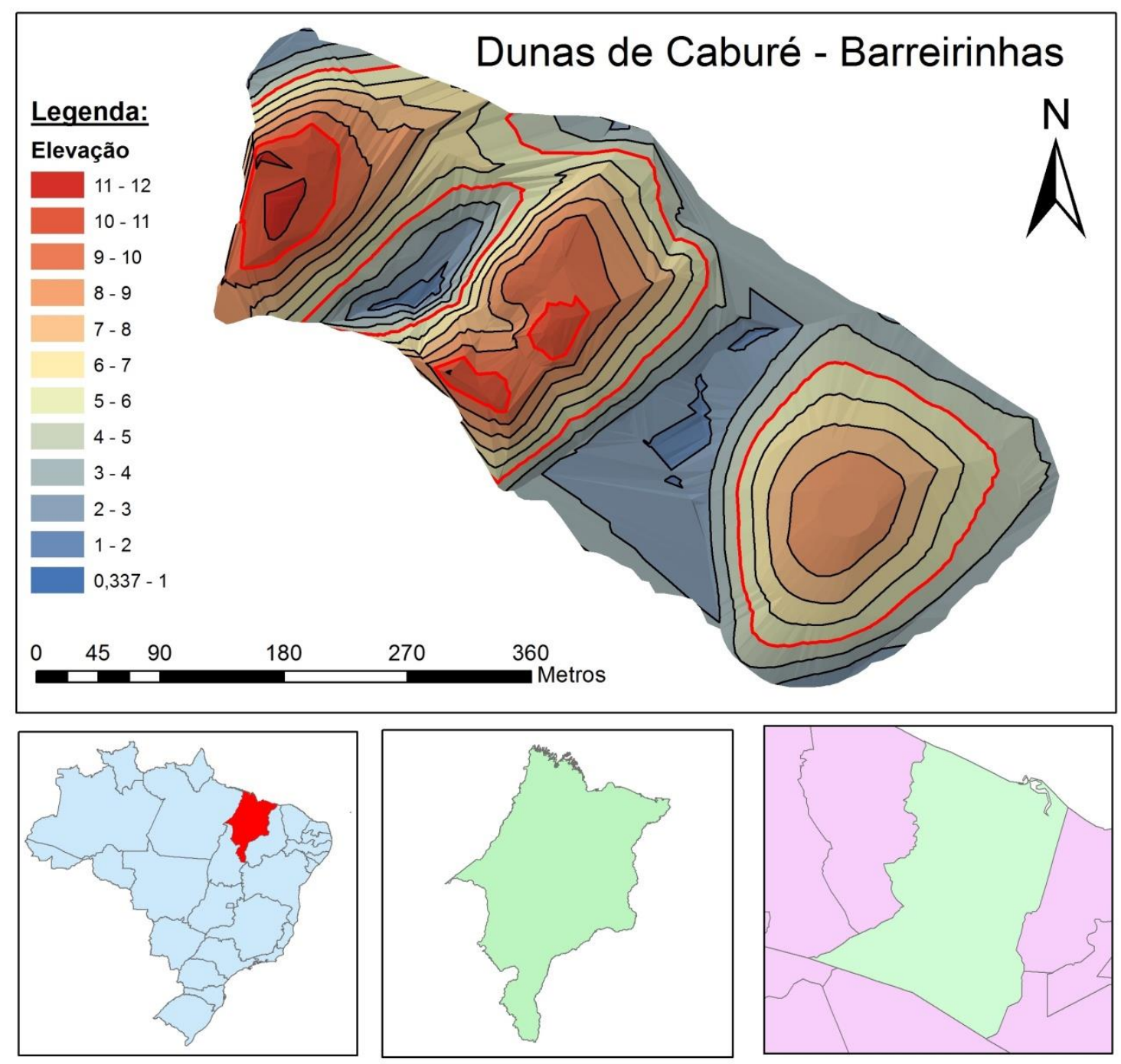

Figura 4 - Modelo Digital de Elevação da Praia de Ponta Dareia, em agosto de 2015.

O relevo da área é típico de região de dunas, com a maioria das altitudes concentradas entre 1,0 e 3,0 $\mathrm{m}$, ou seja, amplitudes de 2,0 m (76,9\% das altitudes tiveram valores entre 1,0 e 3,0 m, 2,3\% inferiores a 1,0 m e 22,2 \% superiores a 3,0 m). No trecho analisado nota-se um padrão na distribuição do relevo que variou principalmente em função da sua localização ao sul da praia do Caburé. Os picos apresentam as maiores altitudes, enquanto as regiões interdunares as menores altitudes. O modelo permitiu a identificação das principais feições morfológicas típicas de dunas zonas de praia, tais como os perfis planos horizontais e inclinados da face de praia emersa, pequenas dunas em formação, depressões e elevações, além de feições morfológicas em erosão.

Utilizando a ferramenta Área e Volume do 3D Analyst obtemos o volume total de 2.446.948,33 m³. 


\section{CONCLUSÕES}

Este trabalho apresentou a análise multitemporal da morfodinâmica sazonal do Parque Nacional dos Lençóis Maranhenses situado em setor costeiro de alta sensibilidade ambiental e sob a influência de atividades antrópicas, entre elas a hoteleira e turística. Os métodos envolveram o uso de técnicas geodésicas de mapeamento de precisão aos problemas da dinâmica costeira de curto prazo, com levantamentos da superfície representadas em modelos digitais de elevação (MDE), coletados em um intervalo de 6 meses entre setembro de 2015 a abril de 2016.

A análise dos resultados permitiu identificar as variações dos MDE em áreas de erosão e deposição de sedimentos, permitindo o entendimento sobre a orientação do transporte sedimentar e a análise do balanço sedimentar. Os resultados mostram que a área teve um balanço volumétrico negativo em 41.976,39 $\mathrm{m}^{3}$ de erosão.

O foco inicial deste trabalho é avaliar o volume de sedimentos das dunas através do posicionamento GNSS. O resultado mostrou que, para o levantamento realizado em novembro de 2015 a duna tinha uma amplitude de $11.485 \mathrm{~m}$ e na base interdunar $0.337 \mathrm{~m}$.

\section{REFERÊNCIAS}

AMARO, V.E.; LIMA, F. G. F.; SANTOS, M.S.T. An Evaluation of digital elevation models to short-term monitoring of a high energy barrier island, Northeast Brazil. World Academy of Science, Engineering and Technology, vol. 76. 2013.

Bianca Cadaval; Miguel da Guia Albuquerque . CARACTERIZAÇÃO DO COMPORTAMENTO DO CAMPO DE DUNAS DA PRAIA DO CASSINO (RS), REGIÃO DA QUERÊNCIA, APÓS A PASSAGEM DE TEMPESTADES. Revista de Engenharia e Tecnologia, V. 7 No . 2, Edição Especial Jun/2015.

Castro ACL, Piorski NM (2002) Plano de Manejo do Parque Nacional dos Lençóis Maranhenses. ICMbio http://www.icmbio.gov.br/portal/biodiversidade/unidades-de-conservacao/biomas-

brasileiros/marinho/unidades-de-conservacao-marinho/2264-parna-dos-lencois-maranhenses [accessed on 06 October 2012]

CORDAZZO, C.V. AND SEELIGER, U. Guia Ilustrado da Vegetação Costeira do Extremo Sul do Brasil, Rio Grande. Universidade Federal do Rio Grande - FURG, 1988, 275p.

CORREIA, F.P; SILVA, L.S; ALVES, S.R.S; GATINHO, M.N; DIAS, L.J.B.S. CARACTERIZAÇÃO DA PAISAGEM DA FAIXA COSTEIRA DO NORTE DA ILHA. In: Simpósio Nacional de Geomorfologia. Goiania. 2006

CORREIA, F.P; SILVA, L.S; ALVES, S.R.S; GATINHO, M.N; DIAS, L.J.B.S. CARACTERIZAÇÃO DA PAISAGEM DA FAIXA COSTEIRA DO NORTE DA ILHA. In: Simpósio Nacional de Geomorfologia. Goiania. 2006 
ESTEVES, L.S.; WILLIAMS, J.J.; DILLENBURG, S.R. Seasonal and interanual influences on the patterns of shoreline changes in Rio Grande do Sul, Southern Brazil. Journal of Coastal Research, v.22, nº5, p.1076-1093. 2006.

ESTEVES, L.S.; WILLIAMS, J.J.; DILLENBURG, S.R. Seasonal and interanual influences on the patterns of shoreline changes in Rio Grande do Sul, Southern Brazil. Journal of Coastal Research, v.22, nº5, p.1076-1093. 2006.

IBGE (INSTITUTO BRASILEIRO DE GEOGRAFIA E ESTATÍSTICA). Informações obtidas da página do IBGE na internet: Disponível em <www.ibge.gov.br>Acesso: 01 janeiro 2012.

IBGE (INSTITUTO BRASILEIRO DE GEOGRAFIA E ESTATÍSTICA). Informações obtidas da página do IBGE na internet: Disponível em <www.ibge.gov.br>Acesso: 01 janeiro 2012.

KLEMAS, V. Remote Sensing Techniques for Studying Coastal Ecosystems: An Overview. Journal of Coastal Research, v. 27, n. 2, p. 2- 17, 2011.

KLEMAS, V. Remote Sensing Techniques for Studying Coastal Ecosystems: An Overview. Journal of Coastal Research, v. 27, n. 2, p. 2- 17, 2011.

MATOS, A.C.O.C. Implementação de modelos digitais de terreno para aplicações na área de geodésia e geofísica na América do Sul. 2005. 335f. Tese (Doutorado em Engenharia de Transportes) - Departamento de Engenharia de Transportes, Programa de Pós-Graduação em Engenharia de Transportes, Universidade de São Paulo, São Paulo. 2005.

MATOS, A.C.O.C. Implementação de modelos digitais de terreno para aplicações na área de geodésia e geofísica na América do Sul. 2005. 335f. Tese (Doutorado em Engenharia de Transportes) - Departamento de Engenharia de Transportes, Programa de Pós-Graduação em Engenharia de Transportes, Universidade de São Paulo, São Paulo. 2005.

Miranda JP; Costa JCL; Rocha CFD. Reptiles from Lençóis Maranhenses National Park, Maranhão, northeastern Brazil. ZooKeys 246: 51-68. doi: 10.3897/zookeys.246.2593, 2012.

MONICO, J.F.G. Posicionamento pelo GNSS: descrição, fundamentos e aplicações. São Paulo: Editora Unesp, p.477, 2008.

MONICO, J.F.G. Posicionamento pelo GNSS: descrição, fundamentos e aplicações. São Paulo: Editora Unesp, p.477, 2008.

REGO, M.; ALBUQUERQUE, P. Redescoberta de Melipona subnita Ducke (Hymenoptera: Apidae) nas restingas do Parque Nacional dos lençóis Maranhenses, Barreirinhas, MA. Neotropical Entomology 35 (3): 416-417, Scientific note, 2006.

SANTOS, A.L.S.; AMARO, V.E.; SANTOS, M.S.T. AVALIAÇÃO DE METODOLOGIA DE AQUISIÇÃO DE DADOS PARA REPRESENTAÇÃO DE FEIÇÕES MORFOLÓGICAS DE PRAIAS ARENOSAS ATRAVÉS DE MODELO DIGITAL DE ELEVAÇÃO. Mercator, Fortaleza, v. 14, n. 2, p. 137-155, mai./ago. 2015. 
SANTOS, A.L.S.; AMARO, V.E.; SANTOS, M.S.T. AVALIAÇÃO DE METODOLOGIA DE AQUISIÇÃO DE DADOS PARA REPRESENTAÇÃO DE FEIÇÕES MORFOLÓGICAS DE PRAIAS ARENOSAS ATRAVÉS DE MODELO DIGITAL DE ELEVAÇÃO. Mercator, Fortaleza, v. 14, n. 2, p. 137-155, mai./ago. 2015.

SANTOS, M.S.T. ; AMARO, V. E.; FERREIRA, A.T.S.; SANTOS, A.L.S. Altimetria GNSS de precisão aplicada ao monitoramento da dinâmica sedimentar costeira de curta duração em escala regional. Boletim de Ciências Geodésicas (Online), v. 19, p. 624-638, 2013.

SANTOS, M.S.T. ; AMARO, V. E.; FERREIRA, A.T.S.; SANTOS, A.L.S. Altimetria GNSS de precisão aplicada ao monitoramento da dinâmica sedimentar costeira de curta duração em escala regional. Boletim de Ciências Geodésicas (Online), v. 19, p. 624-638, 2013.

SANTOS, M.S.T.; AMARO, V.E. Rede Geodésica para o Levantamento Costeiro do Litoral Setentrional do Rio Grande do Norte. Boletim de Ciências Geodésicas, v. 17, n. 4, p. 571-585, 2011.

SANTOS, M.S.T.; AMARO, V.E. Rede Geodésica para o Levantamento Costeiro do Litoral Setentrional do Rio Grande do Norte. Boletim de Ciências Geodésicas, v. 17, n. 4, p. 571-585, 2011.

SANTOS, M.S.T.; AMARO, V.E.; SOUTO, M. V. S. Metodologia geodésica para levantamento de Linha de Costa e Modelagem Digital de Elevação de praias arenosas em estudos de precisão de geomorfologia e dinâmica costeira. Revista Brasileira de Cartografia (Impresso), v. 63, p. 663-681, 2011.

SANTOS, M.S.T.; AMARO, V.E.; SOUTO, M. V. S. Metodologia geodésica para levantamento de Linha de Costa e Modelagem Digital de Elevação de praias arenosas em estudos de precisão de geomorfologia e dinâmica costeira. Revista Brasileira de Cartografia (Impresso), v. 63, p. 663-681, 2011.

SOUTO, M.V.S.; CASTRO, A.F.; GRIGIO, A.M.; AMARO, V.E.; VITAL, H. Multitemporal analysis of geoenvironmental elements of the coastal dynamics of the region of the Ponta do Tubarão, City of Macau/RN, on the basis of remote sensing products and integration in GIS. Journal of Coastal Research, v.39, p.16181621. 2004.

SOUTO, M.V.S.; CASTRO, A.F.; GRIGIO, A.M.; AMARO, V.E.; VITAL, H. Multitemporal analysis of geoenvironmental elements of the coastal dynamics of the region of the Ponta do Tubarão, City of Macau/RN, on the basis of remote sensing products and integration in GIS. Journal of Coastal Research, v.39, p.16181621. 2004.

UEMA - Atlas do Maranhão/Gerência de planejamento e desenvolvimento econômico, Laboratório de Geoprocessamento (LABGEO/UEMA). São Luis: GEPLAN. 2000, 36 p.

ZANARDI, R.P. Geração de Modelo Digital de Terreno a Partir de Par Estereoscópico do Sensor CCD do Satélite CBERS-2 e Controle de Qualidade das Informações Altimétricas. 2006. 94 f. Dissertação (Mestrado em Sensoriamento Remoto) - Programa de Pós-Graduação em Sensoriamento Remoto, Universidade Federal do Rio Grande do Sul, Rio Grande do Sul. 2006. 
ZANARDI, R.P. Geração de Modelo Digital de Terreno a Partir de Par Estereoscópico do Sensor CCD do Satélite CBERS-2 e Controle de Qualidade das Informações Altimétricas. 2006. 94 f. Dissertação (Mestrado em Sensoriamento Remoto) - Programa de Pós-Graduação em Sensoriamento Remoto, Universidade Federal do Rio Grande do Sul, Rio Grande do Sul. 2006. 